\title{
VÍDEO-PERFORMANCE “CORPO-PORTO”: \\ a construção mítica enquanto processo de criação poética
}

VIDEO PERFORMANCE "CORPO-PORTO": the mythical construction as a process of poetic creation

José Flávio Gonçalves da Fonseca

flavio.g.f@gmail.com

Professor Assistente do Curso de Teatro - licenciatura - UNIFAP

\section{Resumo:}

O seguinte artigo análisa a obra intitulada Corpo-porto, uma video-performance realizada pelo coletivo de artistas que desenvolve ações no campo da linguagem da performance art e da intervenção urbana na cidade de Macapá - AP intitulado TensoAtivo, a partir das relações que esta obra apresenta com as questões ouriundas da pesquisa de doutorado que estou desenvolvendo. Tendo como elemento chave a relação com a distância, o deslocamento, os espaços ocupados e habitados, a obra dialoga diretamente com minha pesquisa no que tange o entendimento da relação com a distância e com a condição nômade que se dá na dualidade de um espaço geográfico que ao mesmo tempo que limita, também possibilita uma relação entre dois lugares percorridos. Nesta análise, temos como elemento chave o Rio Amazonas, que se dá como um elemento de construção poética, bem como elemento de construção mítica.

Palavras-chave: Pesquisa performativa, Construção mítica, Coletivo TensoAtivo, Corpo-porto.

\section{Abstract:}

This article analyzes the work entitled Corpo-porto, a video performance by a collective of artists that develops actions in the field of performance art and urban intervention in the city of Macapá, Amapá, Brazil, entitled TensoAtivo, based on the relationships between this work and the questions of the doctoral research that I am developing. Your main elements are the relation with the distance, the displacement, the occupied and inhabited spaces, the work dialogues directly with my research in what concerns the understanding of the relation with the distance and with the nomadic condition that occurs in the duality of a geographic space which at the same time limits, also makes possible a relation between two distant places. In this analysis, we have as key element the Amazon River, which is given as an element of poetic construction, as well as element of mythical

construction.

Keywords: Performative research, Mythical construction, Colletive TensoAtivo, Corpo-porto

O seguinte artigo se propõe a discutir a relação da criação artística enquanto uma criação mítica. Ele se dá a partir da análise do trabalho intitulado Corpo-porto, uma vídeo-performance realizada por um coletivo de artistas denominado TensoAtivo que atua na cidade de Macapá, capital do estado do Amapá, através de ações no campo da linguagem da performance arte e intervenção urbana. 


\section{VÍDEO-PERFORMANCE "CORPO-PORTO": a construção mítica enquanto processo de criação poética}

Este trabalho também se configura como parte integrante de minha pesquisa de doutorado no programa de pós-graduação em Artes da Universidade Federal do Pará, dentro da linha de pesquisa de Poéticas e processos, uma vez que Corpo-porto tem como elemento chave a relação com a distância, o deslocamento, os espaços ocupados e habitados que são elementos que se relacionam diretamente com a pesquisa que estou desenvolvendo, onde busco trabalhar o processo de criação artística a partir da condição de nômade, no que poderíamos estabelecer enquanto uma poética nômade.

Em Corpo-porto a relação com a distância e com a condição nômade se dá na dualidade de um espaço geográfico que ao mesmo tempo que limita, também possibilita uma relação entre dois lugares percorridos. O elemento que estabelece esta dualidade é o Rio Amazonas, que aqui se dará como um elemento de construção poética ao mesmo tempo que se dará como elemento de construção mítica.

A seguir trago a discussão acerca deste processo, apresentando inicialmente ao leitor, como se dá a obra a ser analisada e posteriormente trarei para discussão as relações entre a construção poética e a construção mítica aqui apontada.

Contudo, antes mesmo de adentrar na discussão da obra em questão, é importante traçar alguns apontamentos acerca das perspectivas de pesquisa que tem como pressuposto a prática artística, as ditas pesquisas performativas ou guiadas-pela-prática, uma vez pensando que este artigo analisa uma obra que se desdobra enquanto própria pesquisa.

\section{Pesquisa performativa ou guiada-pela-prática}

Denominamos como pesquisa performativa as abordagens que buscam questionar as práticas de pesquisa que por muito tempo se basearam na dicotomia: quantitativo e qualitativo.

Se por um lado a pesquisa quantitativa esteve presente em investigações cujos os resultados se mostram a partir de aspectos objetivos e que buscam a validação e comprovação a partir de dados, muitas vezes numéricos, por outro lado a pesquisa qualitativa esteve presente na maioria das investigações no campo social, cultural e da educação, trazendo sempre discussões que vão permear o campo dos resultados expressos em texto.

Como nos aponta Hanseman (2006): 
Ao longo da última década, muitos pesquisadores qualitativos têm chegado à mesma conclusão. Limitados pela capacidade das palavras para captar as nuances e sutilezas do comportamento humano, alguns pesquisadores têm utilizado outras formas simbólicas para representar suas reivindicações de conhecimento. (HASEMAN, 2006, pág. 45)

O autor nos aponta para uma tendência da prática de pesquisa que se emancipa da dicotomia quantitativo e qualitativo e vai propor a aceitação de uma terceira vertente de pesquisa que tem na prática a condução de sua investigação, onde esta, (a prática) deixa de se mostrar apenas como método e passa a se estabelecer também enquanto objeto desta pesquisa. Assim, o autor aponta para um modo de pesquisa que é "conduzida-pela-prática" e nos fala ainda que:

A “prática" em "pesquisa conduzida-pela-prática" é essencial - não é um extra opcional; é a precondição necessária de envolvimento na pesquisa performativa. É importante notar que, ao usar o termo performativa para definir esse campo de pesquisa, estou buscando ir além da maneira com que "performativa" está sendo usada atualmente na literatura de pesquisa. (HANSEMAN, 2006, pág. 48)

Assim, a partir deste ponto de vista, da pesquisa "conduzida-pela-prática", nos deparamos com a "pesquisa performativa", que emerge da preocupação dos pesquisadores que se orientavam pela pesquisa qualitativa que em meio as tendências trazidas pelo o que Hanseman (2006) chama de "a vez da performance" que vai alimentar este modo outro de investigação que mesmo tendo relação direta com a pesquisa qualitativa, se configura como uma terceira vertente, uma vez que estabelece modos investigativos que geram resultados que vão além de símbolos dados por texto, mas se abre para uma gama de possibilidades para a discussão de seus resultados.

A pesquisa, então, se detém a criar rastros, desenhar linhas que se dissolvem e se redesenham em um mapa de vetores (uma cartografia). Dessa forma, além da pesquisa performativa, guiada-pela-prática, esta investigação propõe ainda que a cartografia se mostre presente, uma vez tendo em mente o caráter processual de construção dos saberes artísticos em meio a redes corpóreo-midiáticas.

Assim, a pesquisa performativa vai se aproximar da cartografia em meio a sua própria existência enquanto anti-método, estando esta presente na construção de mapas em meio as passagens e rastros dos processos vivenciados.

O mapa é aberto, é conectável em todas as suas dimensões,desmontável, reversível, suscetível de receber modificações constantemente. Ele pode ser rasgado, revertido, adaptar-se a montagens de qualquer natureza, ser preparado por um indivíduo, um grupo, 


\section{VÍDEO-PERFORMANCE "CORPO-PORTO": a construção mítica enquanto processo de criação poética}

uma formação social. Pode-se desenhá-lo numa parede, concebê-lo como obra de arte, construí-lo como uma ação política ou como uma meditação. Uma das características mais importantes do rizoma talvez seja a de ter sempre múltiplas entradas[...] Um mapa tem múltiplas entradas contrariamente ao decalque que volta sempre 'ao mesmo'. (Deleuze e Guattari 1997, pág. 21)

A pesquisa performativa, por via da cartografia, deve ser capaz de buscar pistas para dar corpo à multiplicidade do trabalho em constante construção, assim, deve ser encarada como um meio de experimentação e de produção de devires, um meio de passagem, uma trama processual do decurso da obra-pesquisa.

Portanto, esta pesquisa se mostra em uma multiplicidade que relaciona em rede de fluxos e devires, a pesquisa qualitativa, uma vez lidando com o campo da arte e seus territórios sensíveis, o que também vai trazer a prática como guia e nesse sentido abrindo-se para a pesquisa performativa atravessadas pelo caráter processual que sugere a cartografia.

Nesse sentido, assim como na relação do rizoma em Deleuze e Guattari (1997) estas abordagens metodológicas não se dão em territórios distintos, mas em um fluxo de rede que dissolve qualquer possibilidade de uma se sobressair à outra. A relação aqui se dá em fluxos de desterritorializações e reterritorialização.

\section{Corpo-porto ${ }^{1}:$ Um processo colaborativo entre pessoas e suas distâncias}

Corpo-porto surge da ideia de distância, bem como da ideia de uma comunicação impossível, pelo ponto de vista geográfico, que vai se descontruindo à medida que se estabelece uma relação de construção mítica com o rio Amazonas, gerando com isso outras possibilidades de se comunicar poeticamente com o outro que se encontra distante.

1 É possível assistir o a vídeo-performance na integra acessando o seguinte endereço eletrônico: https://www.youtube.com/watch?v=jUwIeJ5WH_c\&t=25s 


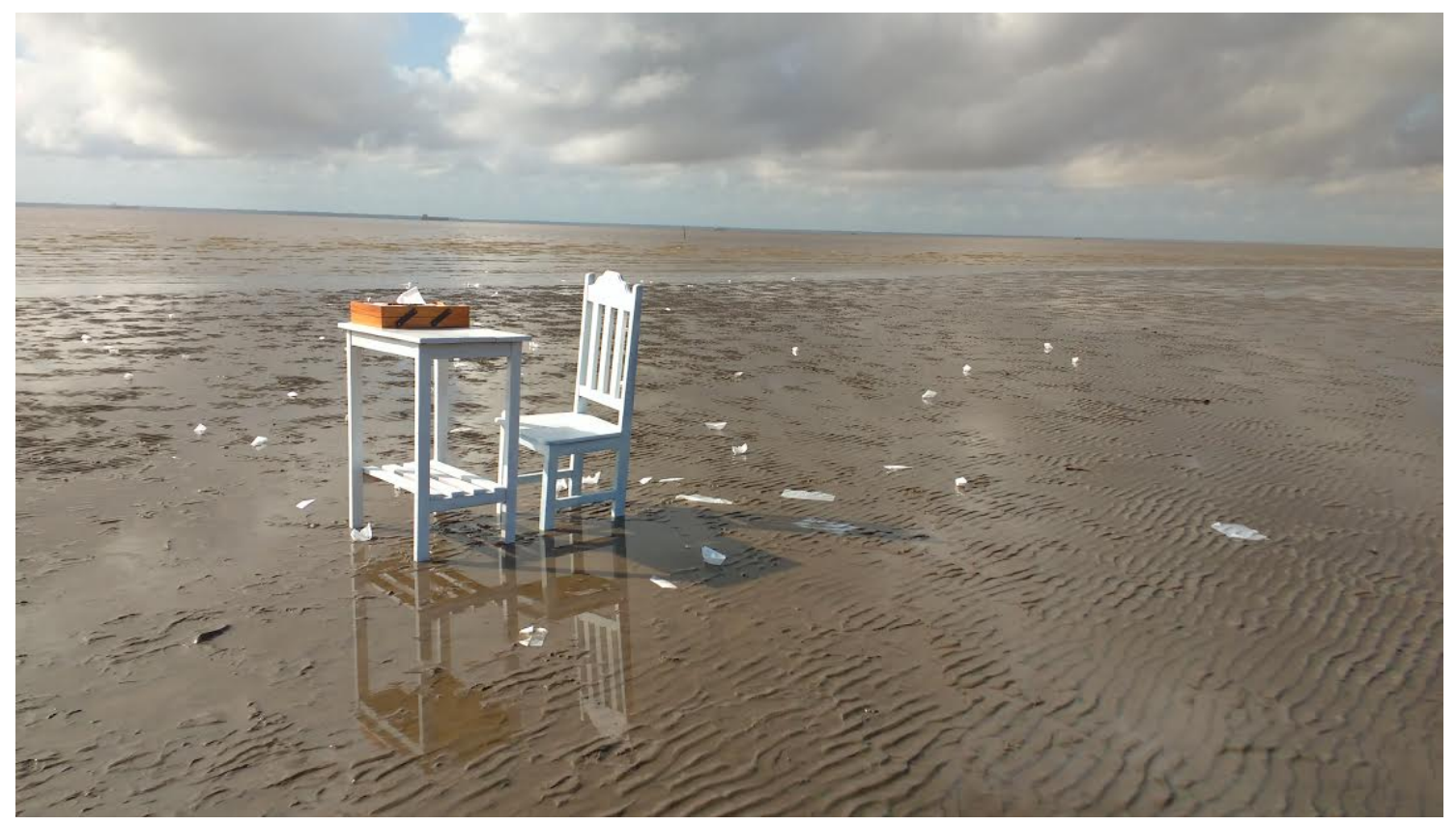

Imagem 1: Registro fotográfico da obra Corpo-porto

Fonte: Acervo pessoal

A vídeo-performance se dá da seguinte maneira: às margens do Rio Amazonas, na orla de Macapá, no período de maré rasa, é colocado uma mesa, uma cadeira, um lápis e um bloco de papel.

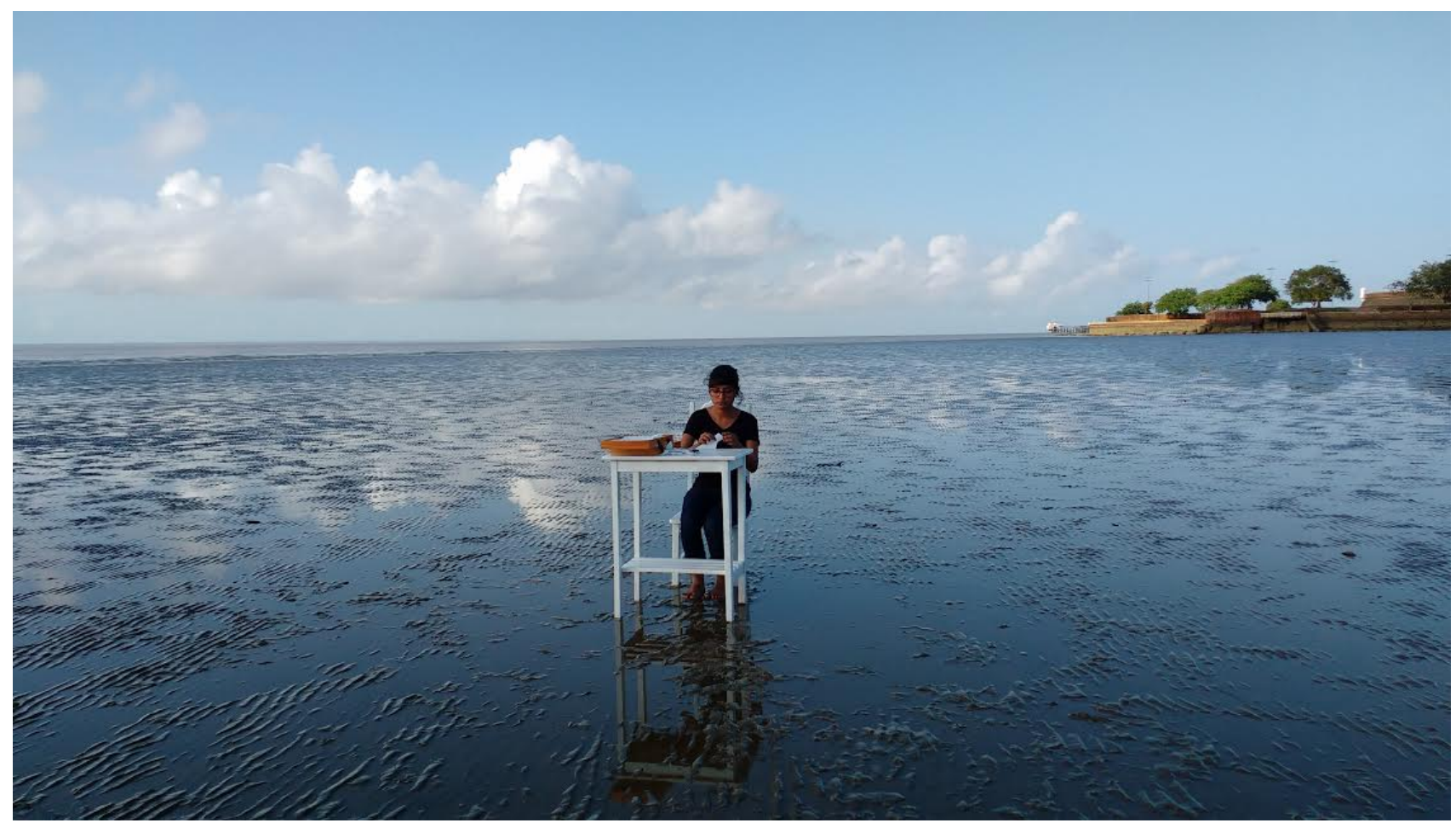

Imagem 2: Registro fotográfico da obra Corpo-porto

Fonte: Acervo pessoal 
Os performers, um por um sentam-se na cadeira e escrevem um recado para alguém distante. Após escrever o recado, o papel é dobrado em forma de barquinho de papel. No final, cada um deposita os barquinhos na beira do rio, que são levados pelas águas do rio no processo de cheia e que se dissolvem posteriormente na sua imensidão.

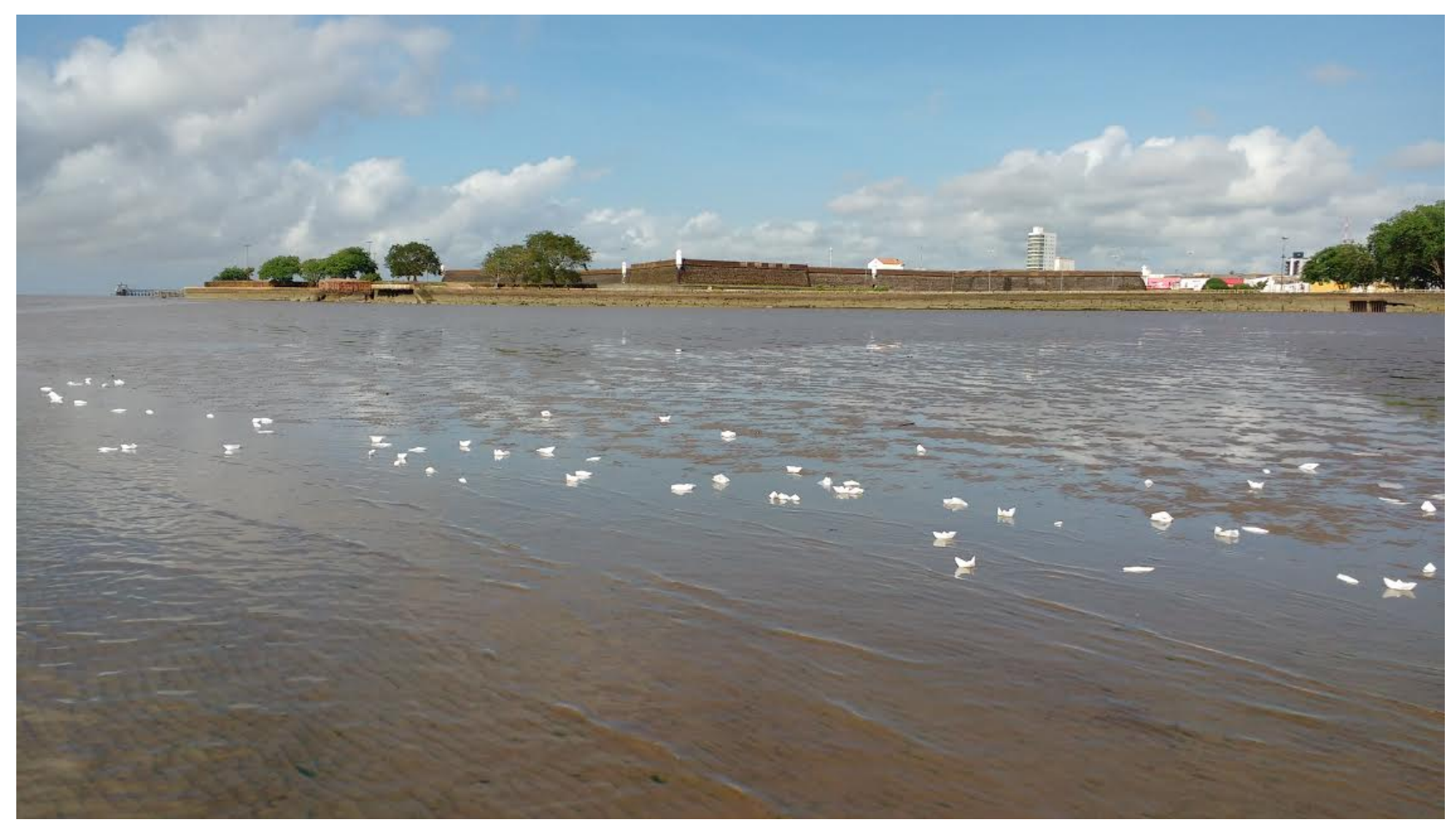

Imagem 3: Registro fotográfico da obra Corpo-porto

Fonte: Acervo pessoal

O Rio Amazonas e sua a relação geográfica e mítica: distanciamentos e aproximações, impossibilidades físicas e possibilidades mítico-poéticas

Se a partir do mito, o homem tenta dar conta de compreender e expressar sua realidade por meio de uma imagem ou representação fabulosa de algo extraordinário, na obra "Portocorpo" o rio Amazonas se configura enquanto uma construção mítica de um elemento capaz de dissolver as distâncias.

Na sua configuração real, o rio Amazonas amplia largamente as distancias geográficas e esgaça o tempo dos deslocamentos. No caso particular do estado do Amapá, esta relação é ainda maior uma vez que não é possível sair do estado (salvo por via aérea) que não seja por meio do 
rio. O Amapá se dá enquanto uma grande ilha cercada por rios por toda parte. O rio Amazonas se dá enquanto grande porta de entrada e de saída do estado. Nesse sentido, o rio se dá enquanto um elemento real de distância. Além disso, especificamente no Amapá, a realidade geográfica, representada pela imensidão do rio dialoga com uma realidade cultural, demonstrando, como nos apresenta Moreira (2012), que a cultura se dá enquanto uma expressão geomorfológica. Desse modo, os aspectos físicos do rio reverberam nas inter-relações culturais do estado. Diria Moreira (2012):

Geograficamente considerada, a Cultura é uma expressão geomorfológica, uma verdadeira camada constitutiva do Planeta, e nesse caráter toma parte saliente na sua economia vital, integrando as forças propulsoras do mecanismo telúrico. Tão essencial é a sua função nesse sentido, que ela se torna mais grandiosa e admirável pelo que desempenha no plano cósmico do que representa no plano estritamente humano, o que importa em dizer que ela é mais grandiosa como fato geográfico do que como realização social. (MOREIRA, 2012, pág. 70)

O processo poético estabelecido na obra Corpo-porto busca trabalhar em uma via contrária dessa condição do rio citada acima. Em um processo artístico, o trabalho proposto busca a partir da construção mítica a possibilidade de encarar o rio como um elemento de diminuição de distâncias. Nesse sentido, pensando a construção poética da obra enquanto construção mítica gera-se a possibilidade de transmutação de uma realidade física (geográfica) a partir de uma operação imaginativa de criação artística. Assim se encontra uma relação direta com o que poderíamos chamar de uma poética do mito. Paes Loureiro (2009) nos fala:

\footnotetext{
A poética do mito deflui de uma dimensão do seu dizer alguma coisa sobre algo sem que, necessariamente, faça algo acontecer. Como tal, constitui-se esse algo que é narrado como uma finalidade e sem a configuração de um fim (na medida em que respiramos uma atmosfera kantiana), o mito, quando oralizado ou transformado em literatura, também não se dirige à provocação ou ao desfrute desse vago estado de crispação suspensa da alma a que denominamos estética. (PAES LOUREIRO, 2009, pág. 152)
}

Assim, a poética do mito no caso específico da obra aqui analisada se dá como citado acima, na dimensão de dizer alguma coisa sem, necessariamente, fazer algo acontecer. Contudo, é importante perceber que este procedimento de "dizer sobre" está permeado por uma potência artística na qual permite, no campo, estético, e por que não dizer mítico, que o acontecimento impossível ocorra por via do imaginário artístico. 


\section{VÍDEO-PERFORMANCE "CORPO-PORTO": a construção mítica enquanto processo de criação poética}

O rio Amazonas, dessa forma se transfigura em um elemento extraordinário e desse modo susceptível a uma construção mítica. Essa construção se dá numa relação do real com o imaginário mítico, atravessado por um elemento de construção poética: a condição de arte.

O mito é uma epifania do imaginário irrompendo na realidade. Semelhante ao teatro é a apresentação de uma ação através de personagens. Como espaço de ilusão equivale à encenação teatral. A encenação de uma espécie de sonho. A imaginação encenando-se a si mesma. (PAES LOUREIRO, 2009, pág. 157)

Assim, na obra Corpo-porto a potência está na impossibilidade de comunicação que é reconfigurada a partir da construção de um imaginário sobre o rio Amazonas criado a partir da proposta poética dos artistas do coletivo. Começa-se aí a elaboração de uma mítica do rio Amazonas que passeia pelo imaginário particular do grupo de artistas que conceberam a obra, bem como dos espectadores que por vez fruíram a vídeo-performance.

Assim, em uma ideia inicial na qual os bilhetes escritos nunca chegariam as mãos dos seus destinatários, começa-se a estabelecer um mito poético onde o rio Amazonas é capaz, em sua grandeza extraordinária, de dar conta da entrega destas mensagens.

Assim, dentro de uma possibilidade poética entre real e imaginário o rio se mostra enquanto este elemento que ao dissolver os bilhetes dobrados em forma de barquinho de papel e suas águas, toma para si as mensagens, e guarda com ele todos os aspectos afetivos depositados naqueles bilhetes.

Nesse acontecimento, onde a maré do rio toma para si os recados deixados em sua margem as mensagens se tornam rio, se tornam água, dando assim menção a um mito construído poeticamente pelo coletivo de artista onde o rio "gentilmente, guarda consigo as mensagens de saudade".

Em um segundo momento desta construção mítico-poética, mais uma vez por meio de uma relação com a realidade e com o aspecto natural do rio, apresenta-se a dinâmica do ciclo da água, que permite que o rio se desloque, transformado em nuvem que transitando pelos céus, rompe e vence distancias e que precipita em forma de chuva nos mais distantes lugares.

Assim, dá-se a segunda etapa deste acontecimento mítico estabelecido poeticamente na obra, onde por meio da chuva resultante da evaporação das águas do rio, que outrora capturou para si os recados deixados em sua margem, leva para os lugares idealizados por meio de um imaginário do coletivo de artistas, o que podemos chamar de uma "mensagem invisível tátil", que 
nada mais seria que as mensagens transformadas em chuva, uma construção mítica do rio que ao dissolver os bilhetes em suas águas, os transporta aos seus destinatários em forma de chuva.

É importante trazer para a discussão a ideia de poética aqui apresentada, que vai ao encontro da noção de "poiêsis" que, em Aristóteles, se mostra enquanto uma ação, um ato de feitura, que em outros termos se configura como uma relação entre um agente que desencadeia um desfecho para uma ato (uma feitura) que pode ser natural ou não-natural e assim, dialoga respectivamente com o fenômeno natural do rio (seu ciclo de cheias e vazantes, o ciclo da água e etc.) e com o fenômeno mítico proporcionado pelo o imaginário poético dos artistas ao conceber a obra - daí um relação poética, nos termos do filósofo grego.

Eis aí a construção de um mito de um rio global, um rio que além de criar suas interligações em sua bacia natural, se comunicando entre seus braços e outros rios deste a sua nascente até o seu ponto de desague, também cria uma rede de braços e bacias globais quando em forma de nuvem carrega consigo aquelas mensagens outrora nele depositadas.

\footnotetext{
O homem completa e culmina, no plano cosmológico, o processo de criação. É através dele que a natureza de reconhece a si própria, tomando consciência da riqueza e da pujança das suas formas e dos mistérios das suas causas e dos seus fins. Ele representa simultaneamente, como salienta Max Sheler, a síntese e a sublimação mais alta do processo cósmico. (MOREIRA, 2012, pág. 71)
}

Aqui temos a imagem de uma bacia hidrográfica mítico-poética que ao mesmo tempo pode ser expressada enquanto um grande fluxo de envio de mensagens para aqueles que estão longe.

E nesse sentido, o recebimento dessas mensagens não se dá por via da leitura, mas por via da experiência tátil, do sentir na pele a mensagem em forma de água. Eis aí a construção do mito de uma mensagem liquida, cuja o veículo se dá por via do movimento natural do rio-mito Amazonas.

\section{REFERÊNCIAS}

ANDERS, Peter. Toward na Architecture of mind. CAiiA-STAR Symposium: Extreme paramenters. New dimensions of interactivity, 2001.

ARISTÓTELES. Poética. Trad. Eudoro de Sousa. São Paulo: Ars Poetica, 1993. 
COHEN, Renato. Working in progress na cena contemporânea. São Paulo: Perspectiva, 2004.

DELEUZE, Gille; GUATARRI, Félix. Mil Platôs. 2ed. São Paulo: Editora 34, 1997. Vol. 4.

GONÇALVES, Flávio. Um argumento frágil. Revista Porto Arte. Porto Alegra-RS, v. 16, n. 27, pág. 137-145, 2009.

HASEMAN, Brad. Manifesto for Performative Research. In: Media International Australia incorporating Culture and Policy. n. 118, Febrary 2006.

KATZ, H.; GREINER, C. Por uma teoria corpomídia. O corpo: pistas para estudos indisciplinares. São Paulo: Editora Annablume, 2005.

LANCRI, Jean. Modestas proposições sobre as condições de uma pesquisa em Artes Plásticas na Universidade. In: O meio como ponto zero: metodologia da pesquisa em artes plásticas. Porto Allegre: Editora da Universidade UFRGS, 2002.

LÉVY, Pierre. $O$ que é virtual? Paulo Neves (Trad.). São Paulo: Ed. 34, 1aㅡ Edição, 8a reimpressão, 2007.

LINS, Daniel. (org.).Cultura e Subjetividade - saberes nômades. São Paulo: Papirus, 1997 MIELIETINSKI, E.M. A poética do Mito. Trad. Paulo Bezerra. Rio de Janeiro: Forense-Universitária, 1987.

MOREIRA, Eidorfe. Ideias para uma concepção geográfica da vida. Belém: SEMEC, 2012.

NOVAES, Adauto. Muito além do espetáculo. São Paulo: SENAC, 2005.

PAES LOUREIRO, João de Jesus. Cultura Amazônica: uma poética do imaginário. 3ạ. Edição. São Paulo: Escrituras Editora, 2000.

jul/dez 2009.

Etnocenologia poética do mito. Revista Ensaio Geral. Belém-PA, v. 1, n. 2, pág. 152-158,

RANGEL, Sônia. Processos de Criação: Atividade de fronteira. In: CONGRESSO BRASILEIRO DE PESQUISA E PÓS-GRADUAÇÃO EM ARTES CÊNICAS - ABRACE, 4., Rio de Janeiro, 2006.

. Perguntas-Passaporte: Mão Dupla Nas Fronteiras Da Criação. In: CONGRESSO BRASILEIRO DE PESQUISA E PÓS-GRADUAÇÃO EM ARTES CÊNICAS - ABRACE, 5., Belo Horizonte, 2008.

SALLES, Cecilia Almeida. Redes da criação: construção da obra de arte. 2a ed. Vinhedo: Horizonte, 2008.

Artigo submetido em 25/02/2018, e aceito em 10/04/2018. 